\title{
Development of typologies of slum settlements: the case of a million plus city of India
}

\author{
P. O. Singh, K. K. Dhote \& N. Soni \\ Department of Architecture \& Planning, \\ Maulana Azad National Institute of Technology Bhopal, India
}

\begin{abstract}
Indian cities are growing at an alarming pace. Indian cities are built in layers and have faced many transformations in context to political, cultural and economic determinants. Their growth has been accompanied by the growth of urban slums. This paper is developed in the background of the presently running central government scheme of slum redevelopment and slum free cities. It aims at developing a typology of urban slum settlements with respect to location, poverty, housing and services of land and identifying the prime factors for considerations in case of suitability assessment of land for development and redevelopment proposals. The typology is developed through a case study of million plus city of central India - Jabalpur. The method identified for deriving typologies is based on the system of development of a matrix which ranks the severity for intervention for prioritization of slums and sector wise intervention on the basis of typologies developed.
\end{abstract}

Keywords: typologies, slum redevelopment, urban land.

\section{Introduction}

Urbanisation is an increase in population and economic activities in the urban areas which leads to further development of towns and agglomerates to contain this rising population. It is a cause and effect of heightened economic progress in a region. Though migration is the key factor, other aspects such as the demand for economic employment, better educational opportunities, health facilities and higher standard of living act as major propellants contributing to the upward trend in urbanization. 
The urbanization process is advanced in developed nations, where $76 \%$ lived in urban areas in 2000, and is projected to increase to $83 \%$ by 2030 . Only $40 \%$ of those in developing countries lived in urban areas in 2000 , likely to be $56 \%$ by 2030. Although developing countries are less urbanized, the rate of urbanization is much higher [1].

Cities are currently home to nearly half of the world's population and over the next 30 years most of the two-billion-plus person increase in global population is expected to occur in urban areas in the developing world. The level of world urbanization today and the number and size of the world's largest cities are unprecedented. At the beginning of the twentieth century, just 16 cities in the world the vast majority in advanced industrial countries-contained a million people or more. Today, almost 400 cities contain a million people or more, and about seventy percent of them are found in the developing world [2].

India's urban areas are defined on the basis of two criteria. First, the state government grants municipal status - corporation, municipal council, notified town area committee or nagar panchayat, etc - to a settlement. Such settlements are known as statutory or municipal towns in the census definition of urban areas. Second, if a settlement does not have an urban civic status, but satisfies demographic and economic criteria, like a population of more than 5,000, a density of 400 persons per square kilometre and $75 \%$ male workforce in the nonagricultural sector, it can be declared urban. Such urban areas are termed census towns. It is important to note that India's urban definition is very broad-based and closely reflects levels of development unlike several other developing countries [3]. Though urbanisation in India is $27 \%$ its urban population exceeds the total population of USA and Brazil. Today India has the second largest urban population in the world and more than two thirds of it lives in the 393 cities that have a population of more than a lakh. During the last 50 years, the rate of growth of urban population of India has been double that of the rate of growth of population. According to the Mckinsey Report Indian cities are likely to house $40 \%$ of the urban population by 2030 . India has seen a phenomenal increase in the number of its metropolitan towns. More than half of the total urban population of India lives in small and medium towns. The cities having population 1 million and more are termed as million plus cities [4]. Although urbanisation has been continuously increasing since the second quarter of twentieth century, it has slowed down after a peak in 1970s. However, the dominance of million plus cities continues to be increasing very strongly since the last two decades.

As per census 2011 Million Plus urban agglomeration (UAs/Towns): out of 468 UAs/Towns belonging to Class I category, 53 UAs/Towns each has a population of one million or above each known as Million plus UAs/Cities, these are the major urban centres in the country with 160.7 million persons (or $42.6 \%$ of the urban population) live in these Million Plus UAs/Cities.18 new UAs/Towns have been added to this list since the last Census. According to the census of India 2011 the top 10 cities of India account for almost 8\% of India's population, produces $15 \%$ of total economic input but occupy only approximately $0.1 \%$ of the total land area. Similarly, the 53 million plus cities 
are estimated to account for $13 \%$ of the population, about one third of the economic output and occupy approx. $0.2 \%$ of the land. The distribution of population can be traced in the entire settlement structure however the highest concentration of urban population is in million plus cities [5].

One of the most significant constraints faced by the governments in the cities of the developing countries has been the failure to ensure adequate supply of affordable serviced land in appropriate locations to meet low income housing needs. The pressure on land is immense as more population moves to urban areas and the city expands to eat away agricultural lands, the inadequate and inequitable supply of serviced land, acts as one of the most significant bottlenecks for housing delivery systems to provide and cope with the need in the urban centers of developing countries. This pressure on land gets converted into encroachments in the form of slums. As statistics shows the total slum population of India accounts to million plus cities are home to approximately $40 \%$ of the total national slum population.

The slum population is constantly increasing: it has doubled in the past two decades. The current population living in slums in the country is more than the population of Britain. India's slum population more than doubled, from 43 million in 2001 to 93 million in 2011 in ten years and it is projected to grow at $5 \%$ per year, adding nearly two million every year, according to official Government data.

\subsection{Reasons for formation of slums on urban land}

Indian cities are built in layers and have faced many transformations in context to political, cultural and economic determinants. The planning system followed after independence was top down master plan approach not giving due consideration for the land to the poorest section. The explosion of population in cities has created tremendous difference between growth and development as most of the Indian cities lack in providing basic infrastructure facilities and the urban poor are the most deprived sector [6]. In context to land the urban poor remain landless due to non affordability/problems related to funds, shooting land values and at the same time generating maximum employment opportunities as the flourished are totally dependent on the poorest sector.

\subsection{Planning interventions for urban poor}

The government is continuously making efforts for the urban poor and in this regard large scale investments on slum up gradation schemes have been proposed. In light of the increasing numbers of urban slum dwellers, governments have recently adopted a specific target on slums, i.e. Millennium Development Goal (MDG) 7, Target 11, which aims to significantly improve the lives of at least 100 million slum dwellers by the year 2020. The Government of India has launched the path breaking programme of Rajiv Awas Yojna (RAY), which envisages making India slum free city. It aims to upgrade housing and civic infrastructure for the settlements of the poor in urban areas, and make adequate urban land available to meet the continuous need for housing land from 
migrants as well as other poor households in the urban areas.RAY emphasizes in situ development, rather than slum relocation, and recognises the importance of land tenure security in the context of the first component of the Slum-free Plan of Action to be prepared at state and city levels. Since land availability is critical for developing housing for the poor, central funds are made available only to the states and cities that can provide land with property rights [7].

Currently under the programme, cities have the responsibility for determining the tenability of slums and identifying them as either 'hazardous' or 'objectionable' for the purposes of the Action Plan. While hazardous slums are defined in terms of environmental problems and health risks, objectionable slums are those that violate legal or master plan norms. In some cases, only a part of a slum may be identified as tenable or non-hazardous.

\section{Method}

The main process of making slum free cities aims at making wholistic interventions. Sector wise interventions are proposed for its upgradation. The purpose of categorizing slums into different typologies will focus target to be very specific to the slum in particular. Previous literatures suggest typologies of slums based on tenureship, location and demographic characteristics but this typology will not only suggest sector wise intervention but will also propose prioritization of slums with respect to is degree of vulnerability.

\subsection{Description of case: Jabalpur slum profile}

The case identified is of a million plus city of central India - Jabalpur which is a class I town ranking fourth in the state with $58 \%$ of urban population to the total population for the districts of the state. The highest slum population, the higher number of slum districts, highest slum distances from city core, highest number of slums with tank location, etc, are some special features of slums of Jabalpur city [8]. Jabalpur has highest slum population, that is, about one-fifth of total slum residents of the state. The multi- functional nature of the city and its centrality attracts a sizeable proportion of socio- economically weaker people not only from nearby villages of the state and also from other adjacent and distant states of the country. The data on migration reveal that Jabalpur has highest number of in- migrants of the state. Despite the highest concentration of slum dwellers of the state, the city occupies the second place $(60.7 \%)$ with regard to literacy rate of class I cities. Jabalpur is the only city in the state where slums are located at places in a radius of $11 \mathrm{~km}$ from the city core while the main concentration of slums is within 1 to $4 \mathrm{~km}$ range where $70 \%$ of the slums can be found [7]. Table 2 explains the distribution of slums in all 13 zones of Jabalpur. The city has been divided in 13 zones, which are further divided in 70 wards. These wards together house 358 slums which have been notified by the Municipal Corporation of the City. People inhabited in these slums are generally for ensuring their livelihoods. 


\subsection{Locational typology}

Most slums in Jabalpur are located along roads or major drains/nallahs, or along railway lines. Others are located on hilly tracts. A majority 124 slums in Jabalpur are located along road margins, while another 80 slums are along drains. As many as forty slums are situated on the slopes of the several hillocks that dot the city. Twenty-nine slums are located in the vicinity of ponds and two slums on river banks. Slums located in low lying areas (17 slums) and those adjoining drains are prone to flooding during the monsoons (Fig. 1).

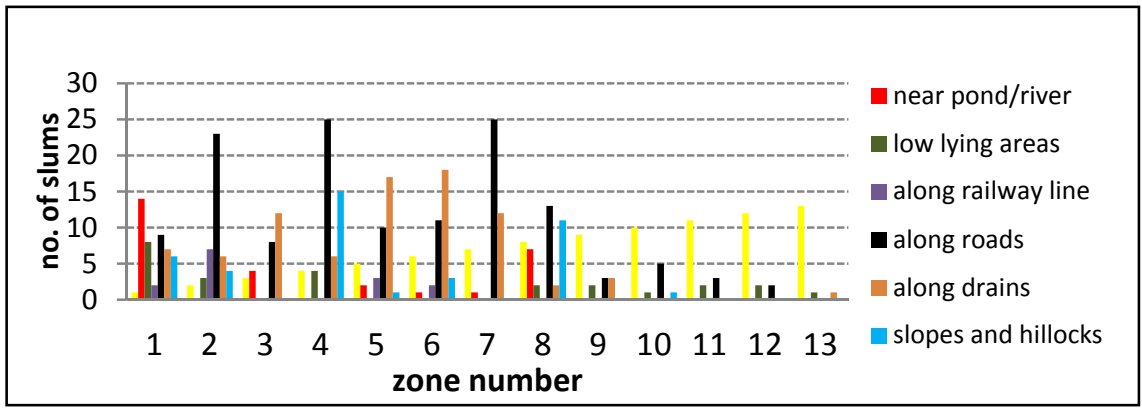

Figure 1: Zone wise location of slums indicating physical feature of the surrounding and adjoining urban land.

\subsection{Methodology}

The urban land typology in this paper attempts to evolve the typology of urban slums and developing a matrix for prioritization of slums depending on the level of severity. The methodology for distribution of the surveyed 358 slums in a 3X3X3 matrix using data on poverty level, housing and infrastructure deficiency. The matrix 3x3x3 was developed on 13 parameters under three components as per table listed below. Each parameter was given weights and the scores were generated. The weightages attached to each parameter is based on research and discussions with the communities. Each of the parameters has been divided in five parts taking the difference of minimum and the maximum values of each parameter and distributing the same in five ranges. Corresponding to each range, a score has been given from 1 to 5 in ascending order of deficiency. In other words the maximum range has been given a score of 5 and the minimum range has been given a score of 1 , while the intermediate ranges have been given the scores of 2, 3 and 4 .

\subsubsection{Housing}

The parameters in this component includes percentage of kuccha house as on priority weightage followed by semi pucca and tenure rights as given below. The percentage deficiency is measured on 5 point scale and total housing score was generated by adding the scores of each parameter. 
Table 1: $\quad$ Housing deficiency score.

\begin{tabular}{|l|c|c|c|c|c|c|}
\hline Parameters & Weights & \multicolumn{5}{|c|}{ Deficiency score range } \\
\hline \% of Kachha HH & 6 & $0-20$ & $21-40$ & $41-60$ & $61-80$ & $81-100$ \\
\hline \% of Semi Pucca HH & 2 & $0-20$ & $21-40$ & $41-60$ & $61-80$ & $81-100$ \\
\hline \% of HH no Legal Rights & 2 & $0-20$ & $21-40$ & $41-60$ & $61-80$ & $81-100$ \\
\hline Deficiency score value & & $\mathbf{1}$ & $\mathbf{2}$ & $\mathbf{3}$ & $\mathbf{4}$ & $\mathbf{5}$ \\
\hline
\end{tabular}

All the parameters have been given scores in similar fashion and the composite score of all the parameters has been calculated by adding the scores of each of the parameters. The composite score is taken as the Housing score. The composite score has thereafter been distributed in three parts taking the difference between the minimum and the maximum score and dividing it in three equal parts and each part has been assigned the final score ranging from 1 to 3 . An illustration of the final scoring system of poverty level is given in Table 2.

Table 2: $\quad$ An illustration of the final scoring system of poverty level.

\begin{tabular}{|c|c|}
\hline Housing condition (total score) & Rank \\
\hline $0-21$ & 1 \\
\hline $21-33$ & 2 \\
\hline 33 and above & 3 \\
\hline
\end{tabular}

\subsubsection{Poverty}

The parameters in this component includes percentage of unemployment as on priority weightage followed by percentage of illiteracy, SC/ST and BPL population as given below. The percentage deficiency is measured on a 5 point scale and total poverty score was generated by adding the scores of each parameter.

All the parameters have been given scores in similar fashion and the composite score of all the parameters has been calculated by adding the scores of each of the parameters. The composite score is taken as the BPL/poverty level score. The composite score has thereafter been distributed in three parts taking the difference between the minimum and the maximum score and dividing it in three equal parts and each part has been assigned the final score ranging from 1 to 3 . An illustration of the final scoring system of poverty level is given in Table 4.

\subsubsection{Infrastructure}

The infrastructure deficiency in each slum has again been calculated on the basis of a few parameters which were derived from physical survey as well as group 
Table 3: $\quad$ Poverty score.

\begin{tabular}{|l|c|c|c|c|c|c|}
\hline \multicolumn{1}{|c|}{ Parameters } & Weights & \multicolumn{5}{c|}{ Deficiency score range } \\
\hline \% Unemployment & 4 & $0-20$ & $21-40$ & $41-60$ & $61-80$ & $81-100$ \\
\hline \% of Illiterate & 2 & $0-20$ & $21-40$ & $41-60$ & $61-80$ & $81-100$ \\
\hline \% HH SC/ST & 1.5 & $0-20$ & $21-40$ & $41-60$ & $61-80$ & $81-100$ \\
\hline $\begin{array}{l}\text { \%of BPL and antyodya } \\
\text { HH }\end{array}$ & 2.5 & $0-20$ & $21-40$ & $41-60$ & $61-80$ & $81-100$ \\
\hline \begin{tabular}{l} 
Deficiency score value \\
\hline
\end{tabular} & & $\mathbf{1}$ & $\mathbf{2}$ & $\mathbf{3}$ & $\mathbf{4}$ & $\mathbf{5}$ \\
\hline
\end{tabular}

Table 4: An illustration of the final scoring system of poverty level.

\begin{tabular}{|c|c|}
\hline Poverty Level (total score) & Rank \\
\hline $0-19$ & 1 \\
\hline $19-32$ & 2 \\
\hline 32 and above & 3 \\
\hline
\end{tabular}

discussions with households in a slum and local councilor, teachers etc. The parameters in this component includes \% deficiency of in-house water supply connection as on priority weightage followed by \% of pucca roads, deficiency of inhouse toilet etc. The percentage deficiency is measured on 5 point scale and total infrastructure score was generated by adding the scores of each parameter.

Table 5: $\quad$ Infrastructure deficiency score.

\begin{tabular}{|l|c|c|c|c|c|c|}
\hline Parameters & Weights & \multicolumn{5}{|c|}{ Deficiency score range } \\
\hline $\begin{array}{l}\text { \% deficiency of } \\
\text { Inhouse Tap } \\
\text { Connection }\end{array}$ & 4 & $0-20$ & $21-40$ & $41-60$ & $61-80$ & $81-100$ \\
\hline $\begin{array}{l}\text { \% deficiency of } \\
\text { Inhouse Toilet }\end{array}$ & 2 & $0-20$ & $21-40$ & $41-60$ & $61-80$ & $81-100$ \\
\hline $\begin{array}{l}\text { \% deficiency of } \\
\text { pucca roads }\end{array}$ & 1.5 & $0-20$ & $21-40$ & $41-60$ & $61-80$ & $81-100$ \\
\hline $\begin{array}{l}\text { \% of solid waste } \\
\text { not collected }\end{array}$ & 0.5 & $0-20$ & $21-40$ & $41-60$ & $61-80$ & $81-100$ \\
\hline $\begin{array}{l}\% \text { deficiency of } \\
\text { pucca Drain }\end{array}$ & 1.5 & $0-20$ & $21-40$ & $41-60$ & $61-80$ & $81-100$ \\
\hline $\begin{array}{l}\% \text { deficiency of } \\
\text { Poles }\end{array}$ & 0.5 & $0-20$ & $21-40$ & $41-60$ & $61-80$ & $81-100$ \\
\hline $\begin{array}{l}\text { Deficiency score } \\
\text { value }\end{array}$ & & $\mathbf{1}$ & $\mathbf{2}$ & $\mathbf{3}$ & $\mathbf{4}$ & $\mathbf{5}$ \\
\hline
\end{tabular}


All the parameters have been given scores in similar fashion and the composite score of all the parameters has been calculated by adding the scores of each of the parameters. The composite score is taken as the infrastructure score. The composite score has thereafter been distributed in three parts taking the difference between the minimum and the maximum score and dividing it in three equal parts and each part has been assigned the final score ranging from 1 to 3 . An illustration of the final scoring system of poverty level is given in Table 6.

Table 6: An illustration of the final scoring system of poverty level.

\begin{tabular}{|c|c|}
\hline Infrastructure deficiency (total score) & Rank \\
\hline $0-22 \%$ & 1 \\
\hline $22-36 \%$ & 2 \\
\hline 36\% and above & 3 \\
\hline
\end{tabular}

\subsection{Development of matrix}

Following the above method each of the 358 slums has been given a rank (element of the 3x3x3matrix) in terms of infrastructure deficiency, housing and poverty. For instance, if a slum has a final score of 1 in terms of infrastructure and 2 in terms poverty and 3 in terms of housing; it is given a rank of $1 / 2 / 3$ in the $3 \times 3 \times 3$ matrix. The matrix is presented in 9 rows and 3 columns. The final matrix of 358 slums is given in Table 7.

A perusal of the matrix below shows that maximum slums are placed in a $1 \times 2 \times 2$ matrix and $1 \times 2 \times 3$ matrix. The worst category of slums is in a $3 \times 3 \times 3$ matrix which shows that in these slums all the three interventions as related to poverty, housing and infrastructure is on priority. It was found that maximum number of slums (> $50 \%$.) are ranking in worst conditions in infrastructure sector. Second highest number of slums $(>25 \%<50 \%)$ were covered in poverty sector and housing sector had the least number of slums $(<25 \%)$ in it. These three typologies along with the location typologies present the categorization of slums of Jabalpur city with respect to its degree of condition. It totally denies the fact that housing and shelter are the prime considerations for the slums as they are skilled to build their own house. The deficiency lies in the supply of land to them and the basic services for their day to day life. It is presumed that authorities may like to concentrate on improving infrastructure facilities as well as socio-economic profile for which they are responsible.

\subsubsection{Location and ownership analysis}

Maximum slums are located in residential areas and many of them on foothills, lake sides and along the nallahs. Most of the slums are on state government land with few of them on private land and on land belonging to railways and forest departments. 
Table 7: $\quad$ Slum matrix.

\begin{tabular}{|c|c|c|c|}
\hline \multicolumn{4}{|c|}{ 3x3x3 Matrix Table } \\
\hline \multicolumn{4}{|c|}{ Housing/Poverty/Infrastructure } \\
\hline $\begin{array}{c}1 / 1 / 1 \\
3\end{array}$ & $\begin{array}{c}1 / 1 / 2 \\
7\end{array}$ & $\begin{array}{c}1 / 1 / 3 \\
1\end{array}$ & 11 \\
\hline $\begin{array}{c}1 / 2 / 1 \\
14\end{array}$ & $\begin{array}{c}1 / 2 / 2 \\
70\end{array}$ & $\begin{array}{c}1 / 2 / 3 \\
49\end{array}$ & 182 \\
\hline $\begin{array}{c}1 / 3 / 1 \\
2\end{array}$ & $\begin{array}{c}1 / 3 / 2 \\
30\end{array}$ & $\begin{array}{c}1 / 3 / 3 \\
13\end{array}$ & 48 \\
\hline $\begin{array}{c}2 / 1 / 1 \\
2 \\
\end{array}$ & $\begin{array}{c}2 / 1 / 2 \\
2 \\
\end{array}$ & $\begin{array}{c}2 / 1 / 3 \\
2\end{array}$ & 6 \\
\hline $\begin{array}{c}2 / 2 / 1 \\
5\end{array}$ & $\begin{array}{c}2 / 2 / 2 \\
34\end{array}$ & $\begin{array}{c}2 / 2 / 3 \\
31\end{array}$ & 70 \\
\hline $\begin{array}{c}2 / 3 / 1 \\
2 \\
\end{array}$ & $\begin{array}{c}2 / 3 / 2 \\
14 \\
\end{array}$ & $\begin{array}{c}2 / 3 / 3 \\
13 \\
\end{array}$ & 29 \\
\hline $\begin{array}{c}3 / 1 / 1 \\
0\end{array}$ & $\begin{array}{c}3 / 1 / 2 \\
0\end{array}$ & $\begin{array}{c}3 / 1 / 3 \\
3\end{array}$ & 3 \\
\hline $\begin{array}{c}3 / 2 / 1 \\
2\end{array}$ & $\begin{array}{c}3 / 2 / 2 \\
14\end{array}$ & $\begin{array}{c}3 / 2 / 3 \\
25\end{array}$ & 41 \\
\hline $\begin{array}{c}3 / 3 / 1 \\
0 \\
\end{array}$ & $\begin{array}{c}3 / 3 / 2 \\
7 \\
\end{array}$ & $\begin{array}{c}/ 3 / 3 \\
13 \\
\end{array}$ & 20 \\
\hline 30 & 185 & 150 & 358 \\
\hline
\end{tabular}

Table 8: $\quad$ Slum location and land ownership.

\begin{tabular}{|c|c|c|c|}
\hline Slum located (land use) & No of slums & Land ownership & No of slums \\
\hline Agricultural land & 2 & Pvt. & $\overline{81}$ \\
\hline Industrial & 7 & State government & 148 \\
\hline Institutional & 2 & Nazul & 1 \\
\hline & & Forest land & 1 \\
\hline Other & 35 & Irrigation department & 6 \\
\hline Other hilly area & 4 & JDA & 1 \\
\hline Residential & 303 & Local unit & 3 \\
\hline & & Maalgujari & 1 \\
\hline Organisational & 2 & Mix & 3 \\
\hline Commercial & 3 & Public & 7 \\
\hline & & Railway & 3 \\
\hline
\end{tabular}

Slums located on hill slopes are dangerous and possibility of any kind of development is difficult and risk taking as the city falls in seismic zone. Most 
of the slums are located on hazardous locations as the land is not occupied by anyone else and so it becomes a potential site for encroachments.

Table 9: $\quad$ Slum locations.

\begin{tabular}{|l|c|}
\hline \multicolumn{1}{|c|}{ Physical status } & No of slums \\
\hline Beside Bada Nala (water channel) & 17 \\
\hline Beside other nala & 27 \\
\hline Beside Talab & 39 \\
\hline Mountain area & 5 \\
\hline Near big transportation & 7 \\
\hline Near railway line & 10 \\
\hline Near river & 250 \\
\hline $\begin{array}{l}\text { Other non dangerous and non } \\
\text { objectionable }\end{array}$ & 3 \\
\hline
\end{tabular}

\section{Findings and conclusions}

The typological process developed for categorization and prioritization of slums presents a detail scenario of the physical, socio-economic and environmental conditions of slums. However, the input of this data for developing redevelopment models, as specified under the scheme of RAY, does not cover the spatial and slum specific ideal models. The typology should provide a slum specific redevelopment model which integrates with the cities fabric as well. The suitability of urban land is limited to the tenability and not the suitable analysis of its existence and development. From the locational typology it is concluded that the selection of land for encroachments are more residential land uses and of state government lands. The prime factors for considerations in case of suitability assessment of land for redevelopment proposals should be based on sensitivity of its environment, cities woven fabric and locational aspects as previous studies have suggested that employment opportunities is the prime factor for formation of slum on a particular land and so its locational typology should be the prime factor of consideration. The objective of making city slum free can only be achieved when the slums after rehabilitation become the integral part of the city fabric. This requires inter weaving of services like transport, water supply and sewerage. The emphasis is not to find solutions unique to the slums but, instead, explore the commonality between the slums and the better parts of the city to integrate the two. As slums are not the causes of urban degradation but the consequences of distorted development, the solutions likewise could treat the slums as mere symptoms and use them to work back into the city fabric to the origins of the problems. 
The study of genesis of slum reveal that the slums, like any other Indian city are in the areas which are eco sensitive, they are potential threat to the dwindling lakes or tals of the Jabalpur city. Many of them are occupying foot hills and along the natural drainage which are converted into nallahs. There are slums in hazardous location like railway line and in industrial areas. All such slums need to be relocated or rehabilitated. The slums which are scattered throughout the city from inner core to periphery varies in density, the inner core are dense than the prescribed or optimal density and lack in services. The sustainability and success of the project of making the city slum free lies in Integration of slum pockets in the city fabric.

The eco-sensitive areas of Jabalpur city include hilly terrains which are rich in vegetation, views and vistas and biodiversity. The river side and the river fronts and the natural drainage are getting polluted. The water bodies are also vulnerable to pollution. The river front of Narmada needs to be developed and maintained for the ongoing socio-cultural activities. Merely Relocation of slums from this area may not solve the problem. A proper drainage system for discharge of storm water, solid waste management and sewerage system should be on priority. There is a strong correlation between the slums, natural drainage paths of the city and its infrastructure and environment. This sensitivity to nature can lead not just to better functioning of infrastructure and cost savings, both at micro and macro levels, but also to a quality of physical environment which is highly desirable. Hence many innovative concepts can be introduced such as topography management, ground cover management, equipotential water distribution, shallow sewerage decentralized sewage treatment such as reed beds and the use of water for recharging the water bodies, recycling of waste water and constructive landscaping to improve drainage and reduce flooding.

The study precisely aimed at studying various typologies of slums exists across cities of different sizes along with type of differences they have i.e. types of tenure, access to basic services and requirements of formal shelter. The study further intends to propose how the slum areas can be classified and graded according to their deficiencies. The research focuses on Identification of different slum typologies based on their characteristics using parameters and indicators. Grading of slums (typologies) for improvement inputs on the basis of deficiencies.

\section{References}

[1] Aromar Revi, 2011 "Urban India 2011: Evidence” Indian Institute of Human settlements India Urban Conference: Evidence and Experience (IUC 2011).

[2] Barney Cohen, 2006 "Urbanization in developing countries: Current trends, future projections, and key challenges for sustainability" Elsevier Technology in Society 28 (2006) pp. 63-80.

[3] Bhagat, R B 2005 "Rural-urban Classification and Municipal Governance in India”, Singapore Journal of Tropical Geography, 26(1): pp. 61-74.

[4] Jain et al., 1993 "Emerging trends of Urbanization in India", Census of India 1993, occasional paper no 1, New Delhi p. 27. 
164 The Sustainable City VIII, Vol. 1

[5] Census of India 2011, provisional population totals, Urbanization trends in cities.

[6] Kundu, A., 2011 “Trends and processes of urbanisation in India” Human Settlements Group International Institute for Environment and Development (IIED) Urbanization and Emerging Population Issues - 6 .

[7] Ray Blue book, 2011 "Guidelines for slum free city planning” Ministry of Housing and urban poverty alleviation (MHUPA), handbook by the Government of India.

[8] City development plan CDP, 2006, “City level reforms” Jabalpur Municipal Corporation. 